\title{
RELACI ONES ENTRE PESO, CONDICIÓN CORPORAL Y PRODUCCIÓN DE LECHE EN VACAS DEL SISTEMA DOBLE PROPÓSITO
}

\section{RELATI ONSHI PS BETWEEN WEI GHT, BODY CONDITI ON AND MILK PRODUCTI ON IN COWS UNDER DOUBLE PURPOSE SYSTEM}

Roger Salgado O, ${ }^{1 *}$ M.Sc, Oscar Vergara G, ${ }^{1}$ M.Sc, J uan Simanca S, ${ }^{2}$ MVZ.

\begin{abstract}
${ }^{1}$ Universidad de Córdoba, Facultad de Medicina Veterinaria y Zootecnia, Departamento de Ciencias Pecuarias. Montería, Colombia. ${ }^{2}$ Ejercicio particular. * Correspondencia: rdsalgado@sinu.unicordoba.edu.co
\end{abstract}

Recibido: Diciembre 27 de 2007; Aceptado: Julio 30 de 2008.

\section{RESUMEN}

Objetivo. Evaluar las relaciones entre peso corporal, condición corporal y producción de leche en respuesta a la suplementación con semilla de algodón. Materiales y métodos. Se utilizaron 13 vacas y se conformaron dos grupos de tratamientos utilizando un diseño al azar: $\mathrm{Gl}(\mathrm{n}=7)$ vacas suplementadas con $2 \mathrm{Kg}$. de semilla de algodón; $\mathrm{G} 2(\mathrm{n}=6)$ vacas no suplementadas. Para el análisis de resultados se emplearon correlaciones de Spearman. Resultados. Se presentaron correlaciones positivas entre la variación de peso corporal y condición corporal $(p<0,05)$ en las vacas suplementadas y no suplementadas. No hubo correlación entre la variación de peso corporal y producción de leche $(p>0,05)$ en las vacas suplementadas; por el contrario se presentaron correlaciones positivas $(p<0,05)$ en las vacas no suplementadas. La variación de condición corporal y producción de leche presentó correlaciones positivas $(p<0,05)$ en las vacas no suplementadas; mientras que no hubo correlación en las vacas suplementadas $(p>0,05)$. Conclusiones. La suplementación con semilla de algodón presentó relaciones positivas importantes entre la variación del peso, condición corporal y producción de leche en vacas de primer parto manejadas bajo condiciones de pastoreo.

Palabras clave: Peso, condición corporal, bovinos, semilla de algodón.

\section{ABSTRACT}

Objective. Evaluate the relationship between body weight, body condition and milk production in response to supplementation with whole cotton. Materials and methods. Two experimental treatments were applied to 13 cows using a randomized design: $\mathrm{G} 1$ $(n=7)$, cows supplemented with $2 \mathrm{~kg}$ of cotton seed, and $G 2(n=6)$, no supplemental seed. 
Results were analyzed using Spearman correlations. Results. There was a positive correlation between body weight and body condition $(p<0,05)$ in the supplemented and non supplemented cows. Although there was no correlation between the variation in body weight and milk production $(p>0,05)$ in the supplemented cows, there was positive correlation $(p<0,05)$ for the non-supplemented cows. The body condition and milk production showed a positive correlation among $(p<0,05)$ in the non-supplemented cows, but not in the supplemented cows $(p>0,05)$. Conclusions. The supplementation with cotton seed had important positive relationship among body weight, body condition, and milk production in cows of first birth managed under pasturing conditions.

Key words: Weight, body condition, bovines, cotton seed.

\section{NTRODUCCIÓN}

La evaluación de la condición corporal en bovinos, es un método utilizado para determinar el grado de reservas corporales independientemente de la estructura, peso vivo y tamaño del animal (1). Varios autores reportaron (2 - 5) que el método es una herramienta valiosa para predecir el desempeño productivo y reproductivo en muchos animales domésticos. Por el contrario, el peso vivo es afectado por el tamaño del animal, el grado de engrasamiento y llenado intestinal (6), los cuales dependen a su vez del estado de preñez, estado de lactación y la fase de crecimiento (7).

Actualmente se sabe que las correlaciones entre peso corporal y producción de leche no han sido consistentes, debido posiblemente al tiempo de lactancia en el que las mediciones son realizadas, asociaciones genéticas entre condición corporal y peso corporal e igualmente del grado de movilización de tejidos a través de la lactancia (8 - 10).

Por el contrario, los promedios de condición corporal durante la lactancia están correlacionados genética y fenotípicamente con rasgos de producción (10 - 12); sin embargo, pequeñas correlaciones entre condición corporal al parto y producción han sido reportadas por Dechow et al (11), mientras que otras investigaciones $(1,5)$ enfatizan la importancia que los cambios tanto en peso corporal como en condición corporal proceden de correlaciones con producción de leche.

\section{MATERI ALES Y MÉTODOS}

Sitio de estudio. El estudio se realizó en una finca localizada en la vereda Canta Rana, municipio de San Carlos (Córdoba), ubicada a $8^{\circ} 45^{\prime}$ latitud norte y $75^{\circ} 22^{\prime}$ longitud oeste, altura de $15 \mathrm{msnm}$, precipitación media anual de $1100 \mathrm{~mm}$, temperatura media anual de $28^{\circ} \mathrm{C}$, humedad relativa de $85 \%$.

Animales. Se utilizaron 13 vacas de primer parto F1 Holstein x Cebú, con una condición corporal al parto de 4 evaluada en una escala de 1 a 5, y se conformaron dos grupos de tratamientos utilizando un diseño completamente al azar (Grupo 1: vacas suplementadas y Grupo 2: vacas no suplementadas).

Manejo de la nutrición. Las vacas del grupo $1(n=7)$ fueron manejadas en pastoreo rotacional en praderas de Angleton (Dychantium aristatum) con suministro permanente de sal mineralizada, agua y fueron suplementadas con $2 \mathrm{Kg}$. diarios/ animal de semilla de algodón. El manejo de las vacas del grupo $2(n=6)$ fue similar al grupo 1 pero sin suplementación.

Recolección de muestras. El peso corporal fue determinado en una báscula fija; la condición corporal fue evaluada subjetivamente por un experto y el puntaje se asignó a cada animal en una escala de 1 a 5, obedeciendo al criterio adoptado por Edmonton et al (13). Esta actividad fue realizada 24 horas después del parto y quincenalmente hasta la decimo cuarta 
semana. La producción de leche/vaca fue determinada mediante pesaje quincenal, hasta los 100 días posparto.

Análisis estadístico. La relación entre peso corporal, condición corporal y producción de leche, se analizaron por medio de correlaciones Spearman, utilizando la información originada durante cada quincena.

Modelo estadístico. El análisis estadístico se realizó mediante el siguiente modelo estadístico:

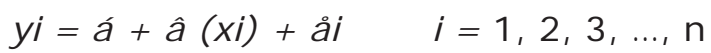

yi = la estimación de la i-ésima observación de la variable dependiente (peso corporal, condición corporal, producción del leche).

xi = la i-ésima observación de la variable independiente (suplementación).

á = intercepto (intersección de la línea de regresión $n$ con el eje y).

$\hat{a}=$ coeficiente de regresión (pendiente de las línea de regresión).

åi = error aleatorio de la i-ésima observación.

\section{RESULTADOS}

En la tabla 1, se muestran los coeficientes de correlaciones de Spearman entre las diferentes variables en estudio, en vacas de primer parto durante las 14 semanas experimentales. Se presentaron correlaciones

Tabla 1. Correlaciónes de Spearman entre las diferentes variables en estudio durante las 14a a semanas posparto en vacas F1 (Holstein x Cebú).

\begin{tabular}{lcc}
\hline \multicolumn{1}{c}{ VARIABLES } & G1 & G2 \\
\hline $\begin{array}{l}\text { Peso corporal vs } \\
\text { Condición Corporal }\end{array}$ & $0.94^{*}$ & $0.81^{*}$ \\
$\begin{array}{l}\text { Peso corporal vs } \\
\text { Producción de leche }\end{array}$ & 0.34 & $0.73^{*}$ \\
$\begin{array}{l}\text { Condición Corporal } \\
\text { vs Producción de } \\
\text { leche }\end{array}$ & 0.54 & $0.81^{*}$ \\
\hline
\end{tabular}

* Significancia estadística $(p<0.05), G 1$ : Suplementadas, G2: No suplementadas. positivas entre la variación de peso y condición corporal en las vacas suplementadas y no suplementadas respectivamente $(p<0,05)$.

No hubo correlación entre la variación de peso corporal y producción de leche en las vacas suplementadas $(p>0,05)$. Mientras en las vacas no suplementadas que se presentaron correlaciones positivas $(p<0,05)$ (tabla 1).

Se presentaron correlaciones positivas $(p<0,05)$ entre la variación de condición corporal y producción de leche en las vacas no suplementadas Por el contrario no hubo correlación en las vacas suplementadas ( $p>0,05)$ (tabla1).

\section{DISCUSIÓN}

Peso corporal versus condición corporal. Las correlaciones encontradas entre la variación de peso corporal y condición corporal en las vacas suplementadas $(r=0,94 ; p<0,05)$ y no suplementadas $(r=0,81 ; p<0,05)$, demuestran que las vacas de primer parto manejadas bajo condiciones de pastoreo, experimentan una perdida de peso simultáneamente con una disminución de la condición corporal durante la lactancia temprana.

Estos resultados concuerdan con los comunicados por Gallo et al (14), Maza et al (15) y Cavestany et al (16) quienes encontraron que las vacas de leche durante la lactancia temprana, utilizan sus reservas corporales para mantenimiento, crecimiento y producción, ocasionando una pérdida significativa del peso y una disminución progresiva de la condición corporal.

Peso corporal versus producción de leche. Los resultados encontrados muestran que se presentaron correlaciones positivas entre la variación de peso corporal y producción de leche en las vacas no suplementadas $(r=0,73 ; p<0,05)$. Es decir, que durante el periodo experimental todas las vacas perdieron peso y al mismo tiempo fueron disminuyendo la producción de leche. Estos resultados coinciden con los 
comunicados por Butler y Smith (3), Gallo et al (14), Gearhart et al (17) Nebel y McGilliard (18), Garnsworthy y Toops (19) y Bauman y Currie (20), quienes afirman que en ganado de leche es común que las vacas presenten balance energético negativo durante las primeras semanas de lactación.

Por el contrario no se presentaron correlaciones $(r=0,34 ; p>0,05)$ entre la variación de peso corporal y producción de leche en las vacas suplementadas. Esto demuestra que las vacas de primer parto manejadas bajo condiciones de pastoreo y suplementadas con 2 kilogramos de semilla de algodón, la variación de peso corporal no afecta la producción de leche.

\section{Condición corporal versus producción de} leche. En la tabla 1, se puede observar que hubo correlación positiva entre la variación de condición corporal y producción de leche en las vacas no suplementadas $(r=0,81$; $p<0,05)$. En este sentido, se podría pensar que la producción de leche durante la lactancia temprana en vacas de primer parto, depende de las reservas corporales (21) posiblemente como consecuencia de una menor ingesta de alimentos durante este periodo, por lo que no alcanza para satisfacer los requerimientos de energía para producción y el animal utiliza sus reservas corporales (22).
Contrario a los resultados encontrados en las vacas no suplementadas, no se presentaron correlaciones entre la variación de condición corporal y producción de leche en las vacas suplementadas $(r=0,54$; $p>0,05)$. Esto demuestra que la variación de condición corporal, en vacas de primer parto manejadas en pastoreo rotacional y suplementación, no afecta la producción de leche $(23,24)$.

En vacas de primer parto no suplementadas con semilla de algodón durante el primer tercio de lactancia se produce una disminución de la condición corporal en la medida que ellas pierden peso. Un mismo comportamiento se presentó entre la condición corporal y la producción de leche. En conclusión, la suplementación con semilla de algodón podría contribuir a mejorar la condición corporal y producción de leche en vacas de primer parto manejadas bajo condiciones de pastoreo.

\section{Agradecimientos}

A la oficina administradora de investigación y extensión de la Universidad de Córdoba por la financiación del trabajo. Al propietario de la Hacienda "Canta Rana", por permitir la realización del estudio.

\section{REFERENCI AS}

1. Waltner S, McNamara J, Hillers J. Relationships of body condition score to production variables in high production Holstein dairy cattle. J Dairy Sci 1993; 76: 3410-3419.

2. Wildman E, J ones G, Wagner P, Bowman R. Dairy cow body condition scoring system and its relationship to selected production characteristics. J Dairy Sci 1982; 65: 495-501.

3. Butler W, Smith R. Interrelationships between energy balance and postpartum reproductive function in dairy cattle. J Dairy Sci 1989; 72: 767-783.
4. Domecq J, Skidmore A, Lloyd J, Kaneene J. Relationship between body condition scores and conception at first artificial insemination in a large dairy herd of high yielding Holstein cows. J Dairy Sci 1997a; 80: 113-120.

5. Domecq J, Skidmore A, Lloyd J, Kaneene J. Relationship between body condition scores and milk yield in a large dairy herd of high yielding Holstein cows. J Dairy Sci 1997b; 80: 101-112.

6. Enevoldsen C, Kristensen T. Estimation of body weight from body size measurements and BCS in dairy cows. J Dairy Sci 1997; 80: 1988-1995. 
7. Koenen E, Groen A, Gengler N. Phenotypic variation in live weight and live-weight changes of lactating Holstein-Friesian cows. J Anim Sci 1999; 68: 109-114.

8. Tveit $B$, Svendsen $M$, Hove $K$. Heritability of hypocalcemia at first parturition in Norwegian cattle: Genetic correlations with yield and weight. J Dairy Sci 1991; 74: 3561-3567.

9. Ahlborn G, Dempfle L. Genetic parameters for milk production and body size in New Zealand HolsteinFriesian and Jersey. Livest Prod Sci 1992; 31: 205-219.

10. Veerkamp R and Brotherstone S. Genetic correlations between linear type traits, food intake, live weight and condition score in Holstein Friesian dairy cattle. J Anim Sci 1997; 64: 385-392.

11. Dechow C, Rogers G, Clay J. Heritabilities and correlations among body condition scores, production traits, and reproductive performance. J Dairy Sci 2001; 84: 266-275.

12. Veerkamp R, Koenen E, De Jong G. Genetic correlations among body condition score, yield, and fertility in 1st parity cows estimated by random regression models. J Dairy Sci 2001; 84: 2327-2335.

13. Edmondson AJ, Lean IJ, Weaber CO, Farber T, Webster GA. Body condition scoring chart for Holstein dairy cows. J Dairy Sci 1989; 72: 68-78.

14. Gallo L, Carnier P, Cassandro M, Mantovani R, Bailoni L, Contiero B, Biltante G. Change in Body Condition Score of Holstein Cows as Affected by Parity and Mature Equivalent Milk Yield. J Dairy Sci 1996; 79: 1004-1015.

15. Maza L, Salgado R, Vergara O. Efecto de la condición corporal al parto sobre el comportamiento reproductivo y variación de peso corporal post-parto de vacas mestizas lecheras. Rev MVZ Córdoba 2000; 6(1): 75-80.
16. Cavestany D, Blanc J, Kulcsar M, Uriarte $G$, Chilibroste $P$, Meikle A, Febel $H$, Ferraris A, Krall E. Studies of the Transition Cow Under a Pasture-based Milk Production System: Metabolic Profiles. J Vet Med 2005; 52: 1-7

17. Gearhart M, Curtis C, Erb H, Smith R, Sniffen C, Chase L, Cooper $M$. Relationship of changes in condition score to cow healt in Holsteins. J Dairy Sci 1990; 73: 3132-3140.

18. Nebel R, McGilliard M. Interactions of high milk yield and reproductive performance in dairy cows. J Anim Sci 1993; 76: 3257-3268.

19. Garnsworthy P, Toops J. The effect of body condition of dairy cows at calving on their food intake and performance when given complete diets. Anim Prod 1982; 35: 113.

20. Bauman D, Currie W. Partitioning of nutrients during pregnancy and lactation: a review fof mechanisms involving homeostasis and homeorhesis. J Dairy Sci 1980; 63: 1514-1529.

21. Edmonson A, Lean J, Weaver D, Farver, T, Webster G. A body condition scoring chart0 for Holstein dairy cow. J Dairy Sci 1989. 72: 68-78.

22. Van Arendonk, Nieuwhof G, Vos H, Korver S. Genetic aspects of feed intake and efficiency in lactating dairy heifers. Livest Prod Sci 1991; 29: 263-275.

23. Ceballos A, Gómez P, Vélez M, Villa N, López L. Variación de los indicadores bioquímicos del balance de energía según el estado productivo en bovinos lecheros de Manizales, Colombia. Rev Col Cienc Pec 2001; 15(1): 13-25.

24. Rukkwamsuk T, Kruip T, Meijer G, Wensing T. Hepatic fatty acid composition in periparturient dairy cows with fatty liver induced by intake of a high energy diet in the dry period. J Dairy Sci 1999; 82: 280-287. 